\title{
DIE GESKIEDENIS VAN DIE SAW GEDENKTEKEN TE FORT KLAPPERKOP MILITÊRE MUSEUM, PRETORIA
}

\author{
A. van der Westhuizen \\ Dokumentasiediens, SANW
}

\begin{abstract}
Die SAW Gedenkteken se lotgevalle is nou verbonde aan dié van die Militêre Museum Fort Klapperkop aangesien die Gedenkteken op die terrein van Fort Klapperkop opgerig is. Weens rasionalisasie is die voortbestaan van Fort Klapperkop Museum onseker. Dit plaas ongetwyfeld dan ook ' $n$ vraagteken agter die voortbestaan van die Gedenkteken.
\end{abstract}

\section{KORT GESKIEDENIS VAN FORT KLAPPERKOP}

Die militêre kwesbaarheid van Pretoria, setel van die destydse Zuid-Afrikaansche Republiek, is deur die Johannesburgse opstande (1895/6) en die Jamesoninval (30 Desember 1895) blootgelê. Om ' $n$ herhaling van hierdie gebeure te voorkom het die ZAR-regering by wyse ' $n$ Uitvoerende Raadsbesluit van 24 Maart 1896 bepaal dat Pretoria van ' $n$ verdedigingstelsel voorsien moet word.' Fort Schanskop, Fort Wonderboompoort, Fort Daspoortrand en Fort Klapperkop is ingevolge hierdie besluit opgerig. Toe die Britse magte olv Lord Roberts op 5 Junie 1900 Pretoria beleër, het die forte geen defensiewe of offensiewe rol gespeel nie aangesien hulle lank reeds onbeman en ontwapen was. Dit was ' $n$ groot teleurstelling vir diegene wat betrokke was by die oprigting van die forte.

Tot 1922 het Fort Klapperkop Britse Kroonbesit gebly, waarna dit ingevolge die Verdedigingsbegiftigingswet (Wet No 33 van 1922) aan die Unieverdedigingsregering oorgedra is. Die regering het die forte op sy beurt tot beskikking van die Departement van Verdediging gestel. ${ }^{2}$ Op 8 Julie 1938, ingevolge Goewermentskennisgewing 1127, is Fort Klapperkop en Fort
Schanskop tot historiese gedenkwaardighede verklaar. $^{3}$

Die gedagte het in die vyftigerjare posgevat om ' $n$ militêre museum in een van die forte te huisves. In 1962 is daar ten gunste van Fort Klapperkop beslis en op 23 Mei 1966 is Fort Klapperkop amptelik as ' $n$ militêre museum deur die Staatspresident C.R. Swart geopen. Die openingseremonie van Militêre Museum Fort Klapperkop het deel gevorm van die amptelike feesvieringe rondom die vyfde herdenking van die Republiekwording. ${ }^{4}$ Die suksesvolle vestiging van die militêre museum by Fort Klapperkop het daartoe gelei dat soortgelyke museums landwyd ontstaan het en in 1973 onder een direktoraat (Direktoraat Militêre Musea) saamgevoeg is. ${ }^{5}$

\section{GESKIEDENIS VAN DIE SAW GEDENKTEKEN}

Die idee vir die oprigting van ' $\mathrm{n}$ gedenkteken het gedurende die middel-sewentigerjare ontstaan, kort na die Angolese Burgeroorlog en Suid-Afrika se toetrede tot die konflik (Operasie Savannah 1975/6). Leidende offisiere in hierdie verband was genl M.A. de M. Malan en genl maj N.N. Webster. Die gedagte was dat ' $n$ gedenkteken opgerig moes word om hulde te

J.Ploeger : Die fort ifikasie van Pretoria; Fort Klapperkop - Gister en vandag (Pretaria 1968), p.1.

Wetten van de Unie van Zuid-Afrika 1922 (Kaapstad 1922) p.381.

Arqief van die Bevelvoerder Militêre Museum Fort Klapperkop (hiema MMFK), houer 2, 1êer HSBD/DMM/2/6/1/2/3.

'Fort Klapperkop - Military Museum', Comm a ndo Jul 1966, p.27.

MMFK, houer 2, lêer HSBD/DMM/2/6/1/2/3. 
bring aan SAW lede wat in diens van hul land gesterf het. ${ }^{6}$ Die gedagte was aanvanklik dat só ' $n$ gedenkteken slegs ter nagedagtenis van die gesneuweldes in Angola opgerig moes word, maar die Raad van Organisasies van Oudgediendes het besluit om die gedenkteken meer omvattend te maak sodat ook diegene wat sedert Republiekwording (1961), ongeag velkleur, in aktiewe diens omgekom het, ingesluit kan word. ${ }^{7}$

Die Raad van Organisasies van Oudgediendes het onderneem om in samewerking met hul eie
- SA Bond van Joodse Oud-Soldate

- SA Legioen

- SA Militêre Verpleegdienstevereniging

- Bond van Oudgediende Weermagsvroue

- Krygsdiensbond van die SA Spoorweë en Hawens

- St Dunstan's SA. ${ }^{8}$

Die SAW Gedenktekenkomitee wat die fondsinsameling en oprigting van die gedenkteken moes hanteer is in die lewe geroep en het die volgende lede gehad: genl maj N.N. Webster, kol P. Venter, brig L.A. Wolmarans, kol P.M.J.

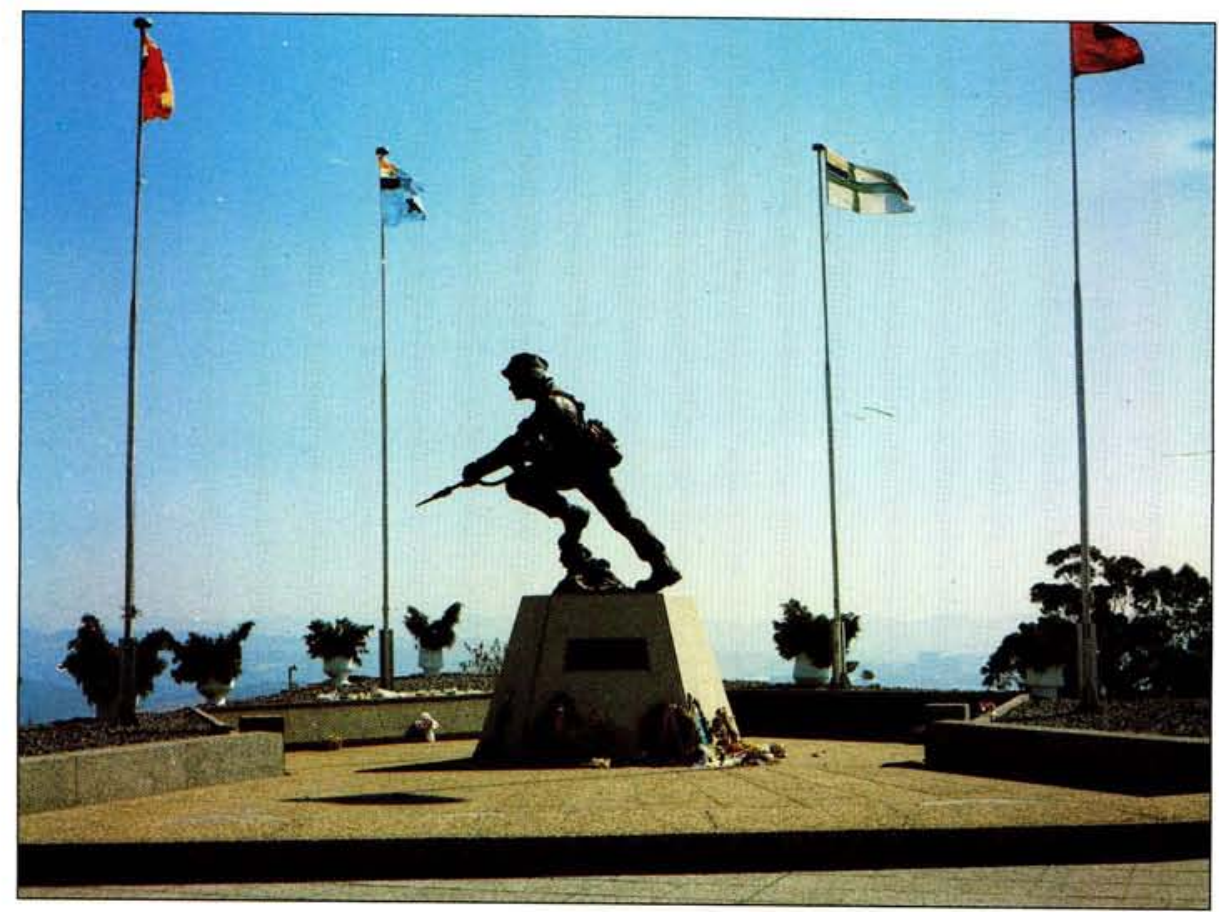

Die Gedenkteken te Fort Klapperkop, Pretoria.

organisasies sowel as met dienende SAWeenhede fondse in te samel vir die oprigting van só ' $n$ gedenkteken. Die nuwe gedenkteken sou bekend staan as die SA Weermaggedenkteken en sou ' $n$ geskenk van die Raad van Organisasies van Oudgediendes wees, waarvan die volgende instansies lede was:

- Die Kannoniersbond

- Vlootoffisiersvereniging van Suidelike Afrika

- M.O.T.H.

- Sappeursvereniging

- SA Lugmagvereniging

- SA Kleurling-oudgediendes se Legioen
McGregor, it kol A.D. Cilliers, kmdt A.W.W. Prevôst, kapt(SAV) D.B. Reaper, kol C. Twomey, brig L.S. Kruger, mnr F.J.A. van Reenen, kol G.W. Snelling, kapt A.G.W. van Tonder, $\mathrm{mnr} H$. van der Merwe en It $L$. Groenewald. ${ }^{9}$ Hierdie Komitee het sy eerste vergadering op 1 Junie 1977 gehou. ${ }^{10}$

Hierdie gedenkteken sou nie die bestaande Weermaggedenktekens soos byvoorbeeld dié van die Lugmag op Baysheuwel of dié van die Kannoniersbond by Potchefstroom, vervang nie. Die enigste ander nasionale militêre gedenkteken op hierdie stadium was die een wat by Delvillebos in Frankryk opgerig is ter

MMFK, houer 56, lêer HS OPS/DMM/517/1/2/16A Notule van 'n vergadering van die Komitee om 'n geskikte plek te vind waarop die voorgestelde Gedenkten by Fort Klapperkop opgerig kan word dd 1 Junie 1977.

Direktoraat Dokumentasiediens Toespraakbank : Tbespraak van mr P.W. Botha 31 Mei 1979. Reeks 305 H 10 ; 'Vir die 550 wat vir RSA geval het', Rapport 23 Mrt 1979; en 'The Klapperkop Memorial', Indaba 33(395), Jul 1979, p.15.

MMFK, houer 47, lêer HSOPS/DMM/517/1/2/1 Soewenierprogram. Toewydingsplegtigheid van SAW Gedenkteken. Ibid.

MMFK, houer 56, 1eer HS OPS/DMM/517/1/2/16A Notule van 'n vergadering van komitee om 'm geskikte plek te vind waarop die voorgestelde gedenkteken by Fort Klapperkop opgerig kan word dd 1 Junie 1977. 
ere van die Suid-Afrikaners wat in die Eerste en Tweede Wêreldoorloë gesneuwel het. ${ }^{11}$ Suid-Afrika se eerste nasionale Weermaggedenkteken sou by Fort Klapperkop wees en die name van alle lede van die SAW van alle bevolkingsgroepe wat in diens van hul land gesterf het, sou op die Gedenkteken aangebring word.

'n Subkomitee van die SAW Gedenktekenkomitee is belas met die keuse vir die ontwerp van die Gedenkteken: kmdt Prevôst, kol McGregor, kapt(SAV) Reaper en mnr Van der Merwe. Hulle het tot die slotsom gekom dat die Gedenkteken eenvoudig dog waardig moes wees. Daar is beslis dat die Gedenkteken sou be-staan uit ' $n$ pentagonale graniet platform. ${ }^{12}$ Die fokuspunt van die Gedenkteken sou ' $n$ standbeeld van 'n Suid-Afrikaanse soldaat (geklee in bosdrag) in aksie wees wat bo-op die granietvoetstuk gemonteer is. Hierdie standbeeld was ' $n$ replika van die miniatuurbeeldjies wat in 1976 toegeken is aan die naasbestaandes van diegene wat in die Angolese veldtog (1975/6) gesterf het. Die beeld sou twee keer lewens-grootte wees en sou na voltooiing ongeveer 670 kilogram weeg. Die beeldhouer was ' $n$ kunsstudent van Pretoria, mnr Henk van der Merwe en kmdt A.W.W. Prevôst (albei lede van die Gedenktekenkomitee) het onderneem om die uitleg en voetstuk vir die Gedenkteken gratis te ontwerp. Rondom die beeld van die soldaat sou ' $n$ lae ringmuur opgerig word waarop die name van die gesneuweldes en die jaartal waarin hulle gesneuwel het, aangebring sou word. Die inskripsie op die muur sou lees: "Opgerig ter nagedagtenis aan alle lede van die Lëer, Lugmag en Vloot wat hulle lewens vir hulle land opgeoffer het. ${ }^{13}$ Die naamlys het in 1979586 name bevat en sou daarna jaarliks aangevul word. Die totale koste van die gedenkteken sou ongeveer R30 000 beloop. $^{14}$

Die gedenkteken te Fort Klapperkop is op 31 Mei deur P.W. Botha, Eerste Minister en Minister van Nasionale Veiligheid onthul. Die onthullingseremonie het saamgeval met die feesvieringe rondom die herdenking van Republiekdag. Die destydse Hoof van Militêre Veterane Sake en voorsitter van die Raad van Organisasies van Oudgediendes van die RSA, genl maj N.N. Webster, het die monument aan die

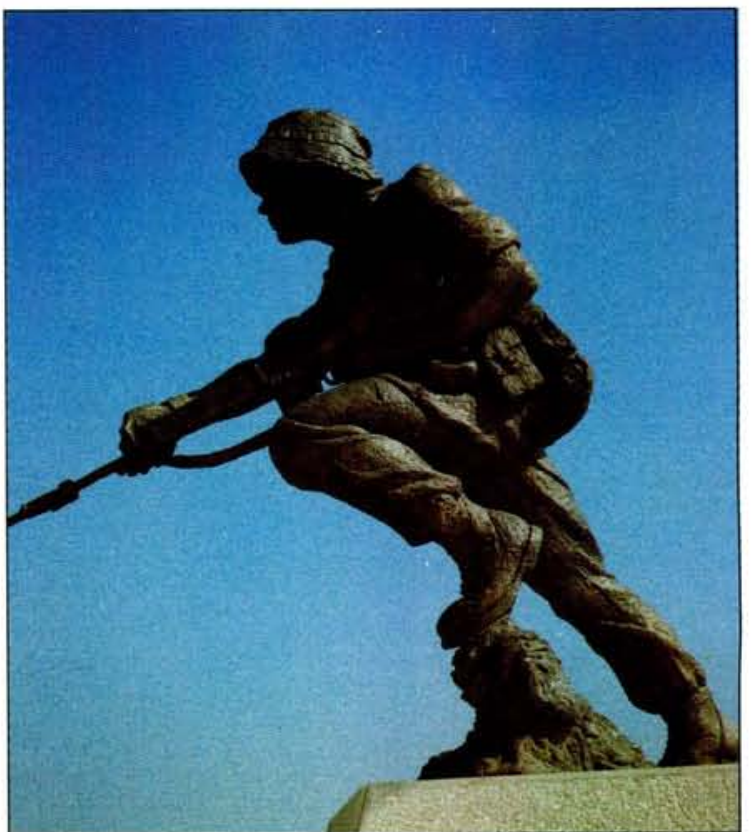

Die fokuspunt van die gedenkteken - ' $n$ SuidAfrikaanse soldaat geklee in bosdrag.

SAW oorhandig. By hierdie gedenkteken was die name op marmertablette op die ringmuur gegraveer van die 586 lede van die SAW wat sedert Republiekwording in die verdediging van die RSA gedood is..$^{15}$ Die Hoof van die SAW op daardie tydstip, genl M.A. de M. Malan, het die Gedenkteken namens die SAW in bewaring geneem. In sy toespraak het genl Malan die gedenkteken beskryf as ' $n$ helde-akker vir die SAW op eie bodem. ${ }^{16}$ Die onthullingseremonie is bygewoon deur etlike duisende toeskouers asook lede van die Lëer, Lugmag, Vloot en die Suid-Afrikaanse Geneeskundige Dienste. Min P.W. Botha het in sy toespraak daarop gewys dat die Gedenkteken nie net Weermagslede wat gesneuwel het vereer nie, maar dat dit ook dien as "waarskuwing dat die totale aanslag teen Suid-Afrika niemand op grond van kleur, taal of geloof ontsien nie". ${ }^{17} \mathrm{Hy}$ het ook opgemerk dat die eenvoud van die gedenkteken se ontwerp die soldate se opregte toewyding simboliseer. By hierdie geleentheid het min Botha asook genl Malan ' $n$ jaarlikse gedenkdiens by Fort Klapperkop op 31 Mei in die vooruitsig gestel om eer te betoon aan die SAW-lede wat in die voorafgaande 12 maande die lewe gelaat het. Vanweë die talle herdenkingsdienste rondom Republiekdag is daar na verloop van twee jaar en na oorlegpleging met die Raad van Organisasies van Militêre Ve-

D. Kruger, 'Premier maak planne or monument bekend. Soldaat vereer met vlam', Transvaler 1 Jun 1979.

MMFK, houer 56, lêer HS OPS/DMM/517/1/2/16A Notule van 'n vergadering van die komitee om 'n geskikte plek te vind waarop die voorgestelde gedenkteken by Fort Klapperkom opgerig kan word dd 1 Junie 1977.

MMFK, houer 56, lêer HS OPS/DMM/517/1/2/16A Notule van die Gedenktekenkomitee da 15 Augustus 1978. 'Monument byna klaar', Oggendblad 4 Aug 1978.

D. Kruger, 'Premier maak planne or monument bekend. Soldaat vereer met vlam', 'Transvaler 1 Jun 1979. MMFK, houer 47, lêer HS OPS/DMM/517/1/2/1 Soewenierprogram. Toewydingsplegtigheid van SAW Gedenkteken.

D. Kruger, 'Premier maak planne oor monument bekend. Soldaat vereer met vlam', Transvaler 1 Jun 1979. 
terane van die RSA besluit dat die jaarlikse gedenkdiens by Fort Klapperkop nie meer op 31 Mei sal plaasvind nie, maar wel jaarliks op die tweede Sondag in Augustus. ${ }^{18}$

Voor die onthulling van die Gedenkteken is die lys van die name wat op die Gedenkteken aangebring gaan word gepubliseer sodat foute en regstellings aangemeld kon word. Sodanige regstellings moes by kol P.J. Albertse, Direkteur van die Personeelinformasie Buro, aangemeld word. ${ }^{19}$ Probleme het toe al reeds ontstaan oor die bepaling van wanneer ' $n$ persoon as ' $n$ amptelike sterfgeval geklassifiseer kon word. Riglyne rakende dié kwessie is eers vasgelê in Aanhangsel B van HSAW Direktief No HSAW/1/3/84 dd 1 Augustus 1984 getiteld: "Administrasie prosedure vir teraardebestelling van bepaalde lede van die Veiligheidsmagte (SA Weermag, SA Polisie en SA Spoorwegpolisie)". Aanhangsel B bepaal die kategorieë van sterfgevalle onder lede van die Weermag wat kwalifiseer vir amptelike graftetoekenning in veiligheidsmagte-akkers en vir vermelding of op ererolle, gedenkstene, monumente ens.

"Tensy ' $n$ lid van die Veiligheidsmagte as gevolg van wettige teregstelling sterf of as gevolg van ' $n$ oortreding van of misdaad teen die Reglemente van Dissipline van die Veiligheidsmagte of die Strafreg van die RSA, sal elke lid van die Veiligheidsmagte as ' $n$ amptelike sterfgeval beskou word wanneer hy/sy te sterwe sou kom:

a. In enige gebied binne of buite die RSA in oorlogstyd.

b. In ' $n$ vyandelike of operasionele gebied gedurende enige tyd van konflik anders as konvensionele oorlog.

c. Gedurende opleiding ter voorbereiding vir operasionele diens.

d. Tydens ' $n$ amptelike reis na of van ' $n$ operasionele gebied.

e. Tydens uitvoering van bepaalde antiterroriste of teeninsurgensietake.

f. Tydens ' $n$ reis na ' $n$ benoemde/aangewese aanmeldpunt as gevolg van ' $n$ mobilisasiebevel of op reis na ' $n$ demobi- lisasiepunt na afloop van mobilisasiebevel.

g. As gevolg van enige optrede, op enige plek, te enige tyd, deur enige vyand van die RSA of deur enige terroris(te), insurgent(e) of ander persoon of persone wat die RSA en sy volkere kwaadgesind is.

h. Binne twee jaar (vyfhondred-en-dertig dae) nadat hy/sy met ' $n$ ongeskiktheidspensioen uit diens getree het agv siekte, beserings of wonde opgedoen onder omstandighede of gebeure soos in $a, b$, $c, d, e, f$ en $g$ uiteengesit, as direkte gevolg van sulke siekte, beserings of wonde."20

Die gravering van die name op die marmertablette is aanvanklik deur die Hoof van Militêre Veterane Sake en die argitek, wat vir die uitleg van die gedenkteken verantwoordelik was, behartig. ${ }^{21}$ Die gedenkteken is in 1979 aan die SAW oorhandig, maar dit is nie duidelik wie daarna vir die Gedenkteken verantwoordelik was nie. Dit wil voorkom asof dié taak hierna deur die Direkteur van die Personeelinformasie Buro op homself geneem is. Kol P.J. Albertse merk self in ' $n$ memorandum op: "Hierdie taak en die verantwoordelikheid om beslissing te vel van welke lede kwalifiseer al dan nie berus uitsluitlik by PIB". ${ }^{22}$ Die taak is klaarblyklik op geen stadium aan PIB opgedra nie. Dit het klaarblyklik voortgespruit uit die PIB se aanvanklike betrokkenheid en die feit dat hierdie organisasie op daardie tydstip verantwoordelik was vir die administrasie van oorlogsgrafte. ${ }^{23}$ Volgens kol Albertse het hierdie taak die volgende ingesluit:

a. Verskaffing van die naamlys vir die voorafgaande jaar.

b. Proeflees van die naamplate voordat die finale gravering gedoen word.

c. Reël vir die oprigting van die naamplate by die Gedenkteken. ${ }^{24}$

Gedurende die vroeë tagtigerjare, namate die felheid van die bosoorlog toegeneem het, het die Gedenkdiens by Fort Klapperkop ook in belangrikheid toegeneem. In 1980 het 150

\footnotetext{
HSAW Beleidsdirektief HSAW/1/29/81 dd 20 Mei 1981 HSP/D SER/512/2/1/B.

'Nog gesneuweldes', Rapport 15 Apr 1979.

HSAW Direktief, HSAW 1/33/84 dd 1 Augustus 1984.

Registrasie Personeel Argief en Reserwes (Dokumentasiediens) : Memorandum van PIB aan HDMI. HSP/PIB/517/5 dd 20 Augustus 1981.

Ibid.

MMFK, houer 46, lêer KO/DMM/517/1.

Memorandum van PIB aan HDMI HSP/PIB/517/5 dd 20 Augustus 1981.
} 
lede van die Suid-Afrikaanse Legioen op ' $n$ pelgrimstog na Italië, grond van Fort Klapperkop in ' $n$ kruik van deurskynende albaster saamgeneem om dit by die Suid-Afrikaanse oorlogsbegrafplaas in die kapel by Castiglione te laat. Hierdie grond sou ' $n$ simbool wees van die band tussen die Suid-Afrikaners wat in die Tweede Wêreldoorlog gesneuwel het en dié wie se name op die naamplate by Fort Klapperkop gegraveer is. ' $n$ soortgelyke kruik met grond van Castiglione is by die Zonderwaterbegraafplaas by Cullinan geplaas waar vele Italiaanse krygsgevangenes in die Tweede Wêreldoorlog begrawe is. ${ }^{25}$

Die hele kwessie rondom die aanbring van die name by die SAW Gedenkteken is nie op ' $n$ vaste grondslag bedryf nie. Dit het die volgende probleme vir PIB geskep:

a. Dit was nie duidelik wie vir die gravering op die naamplate aanspreeklik moes wees nie.

b. Indien daar veranderings of verskuiwings aan die Gedenkteken gedoen moet word, was daar nie duidelikheid oor watter instansie genader moet word nie.

c.

Geen vaste rëels het bestaan vir die uitnodiging van die naasbestaandes van diegene wie se name op die ererol vermeld word nie.

d. PIB was verantwoordelik vir die aanbring van die name maar was uitgesluit van die rëelings vir die herdenkingsdiens. ${ }^{26}$ Kol Albertse het voorgestel dat ' $n$ vaste beleid mbt die verantwoordelikheid vir die Gedenkteken opgestel moet word en dat ' $n$ vaste komitee, bestaande uit verteenwoordigers van die Lëer, Lugmag, Vloot en Geneesheer-Generaal benoem moet word om PIB by te staan in die opstel van die naamlys vie die ererol. Hierdie aangeleentheid sou deel uitmaak van Projek KREEF. ${ }^{27}$

Dit wil ook voorkom asof daar van tyd tot tyd ' $n$ klemverskuiwing voorgekom het in die vereistes waaraan sterfgevalle moes voldoen om vermelding op die ererol te kry. In 'n skrywe HSP/PIB/517/5 gedateer 10 September 1987 word die kriterium vir benoeming op die Gedenkrol as volg beskryf: die lid moes in aksie, gedurende opleiding of in die uitvoering van sy amptelike pligte gesneuwel het. Dan volg ' $n$ deel wat nie in HSAW Beleidsdirektief 1/ 33/84 dd 1 Augustus 1984 aangespreek word nie: uitgesluit by bogenoemde bepaling was sterftes agv natuurlike oorsake, selfmoord en privaat motorvoertuigongelukke. ${ }^{28}$

Benewens die gebrek aan behoorlike riglyne vir die aanbring van die name op die ererol het die aantal mense wat jaarliks die gedenkdiens bygewoon het algaande minder geword. ' $n$ Waarskynlike verklaring vir hierdie swak bywoning is die feit dat die oorlog teen terrorisme afgeskaal is en dat daar gevolglik minder SAW lede in die verdediging van hul land sneuwel. Die naasbestaandes van diegene wat wel gesneuwel het, woon ook nie meer so geredelik die Gedenkdiens by nie. Verder val die Gedenkdiens op die tweede Sondag in Augustus wanneer dit gewoonlik koud en winderig is. Nog ' $n$ rede vir die swak bywoning is die aantal gedenkdienste wat in hierdie tyd in en om Pretoria gehou word. ${ }^{29}$

Verskeie persberigte in die afgelope jaar het ook die agteruitgang van die terrein by Fort Klapperkop geskets byvoorbeeld:"Shut fort has mum distraught" (Pretoria News 28/12/93) en "Dismay over state of Fort Klapperkop" (Pretoria News 30/12/93). Hierdie berigte is voorafgegaan deur berigte waarin aangekondig word dat Kommandement Noord-Transvaal ingevolge besparingsmaatreëls nie meer Fort Klapperkop en Fort Schanskop gaan bedryf nie. Die forte se administrasie en beheer sou aan die Stadsraad van Pretoria oorgedra word. ${ }^{30}$

Persberigte soos die bogenoemdes kan by die publiek die indruk wek dat die SANW nie meer vir die Gedenkteken omgee nie. In 'n onderhoud met die media skryf kol M. Kinghorn van Kommandement Noord-Transvaal die agteruitgang van die museum aan rasionalisasie toe: daar is net nie genoeg personeel om die fort instand te hou nie. Hy het egter bevestig dat die SAW Gedenkteken hoog op die lys van prioriteite is. ${ }^{31}$

Volgens ' $n$ artikel in Paratus is 'n werkgroep

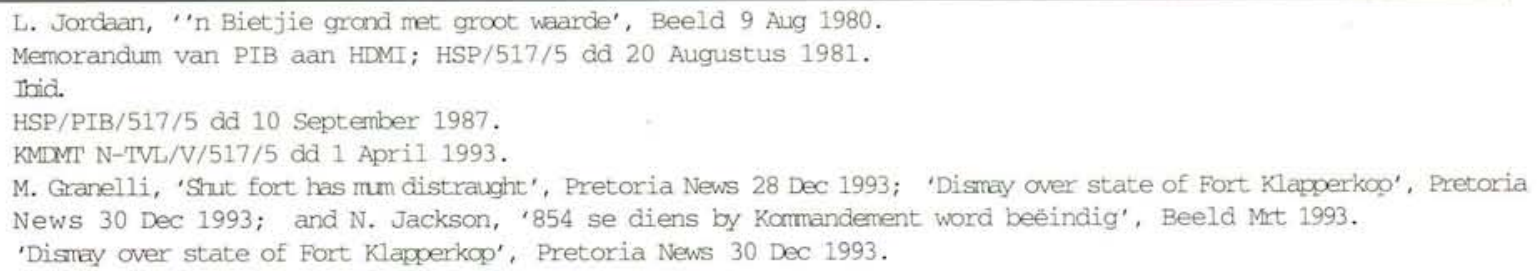


van betrokkenes deur die SAW saamgestel om te besin oor die toekoms van Fort Klapperkop en Fort Schanskop. Die werkgroep het bestaan uit die Departement van Openbare Werke, Onderwys en Kultuur, Nasionale Opvoeding, die Transvaalse Provinsiale Administrasie, die Stadsraad van Pretoria, die Beheerraad van die Voortrekkermonument, Nasionale Kultuurhistoriese Museum, die Stigting Simon van der Stel en die Genootskap van Oud Pretoria. Hierdie werkgroep sou hul werksaamhede teen 31 Januarie 1993 voltooi het. ${ }^{32}$

Die Direktoraat Bevelskommunikasie van die Leër het ' $n$ ondersoek uitgevoer en tot die slotsom gekom dat "die gebrek aan kundige personeel, mannekrag en fondse" die voortbestaan van die musea kortwiek. ${ }^{33}$ Gevolglik het die Minister van Verdediging op 8 November 1993 magtiging verleen vir die rasionalisaie van die militêre musea onder die SA Leër se beheer. Ingevolge hierdie besluit is opdrag gegee dat die museums van die Lëer teen 31 Maart gerasionaliseer moet wees en beslis dat die fasiliteite van Fort Klapperkop en Fort Schanskop aan die Departement Openbare Werke en Grondsake (DOW en G) teruggehandig word. ${ }^{34}$ Volgens ' $n$ seinberig dd $3 / 1 / 94$ het die SA Leër reeds ingestem om van die forte afstand te doen. $\mathrm{Na}$ onderhandelings met belanghebbende instansies het Afdeling Logistiek op $29 \mathrm{Ju}$ nie 1993 die forte aan DOW teruggehandig vir beskikking. ${ }^{35}$

Dit blyk dus ' $n$ voldonge feit te wees dat Fort Klapperkop aan ' $n$ eksterne organisasie oorgedra gaan word. Onderhandelings tussen DOW en die Stadsraad is ' $n$ uitgerekte proses en dit wil voorkom asof ' $n$ ooreenkoms nog nie bereik kon word rakende die forte nie. Verskeie aspekte moet egter nog ondersoek word. Ingevolge die Verdedigingsbegiftigingswet (Wet No 33 van 1922) kan die eiendomme waarop die forte geleë is, alleenlik aan die Raad vir Nasionale Gedenkwaardighede oorgedra word. Indien dit egter oorgedra sou word aan enige ander instansie sal daar markverwante vergoeding betaal moet word. ${ }^{36}$ Die Raad vir Nasionale Gedenkwaardighede het laat blyk dat hulle tans nie oor die fondse beskik om die forte oor te neem nie. Volgens die Administrateur van
Transvaal, D.J. Hough, stel die Stadsraad wel belang om Fort Klapperkop deel te maak van hulle kultuurroete. ${ }^{37}$ Dit lyk asof daar gepoog word om die verkoop van die twee forte aan mekaar te koppel. Indien die Stadsraad nie belang sou stel om beide Fort Klapperkop en Fort Schanskop as ' $n$ "pakket" te aanvaar nie sal die Staat heel moontlik die forte verkoop of verhuur $\mathrm{dmv}$ openbare vendusie of tender. ${ }^{38}$ Die Raad van Militêre Veterane Organisasies en ander besorgdes het egter bedenkinge oor toegang tot die SAW Oorlogsgedenkteken by Fort Klapperkop indien die museum aan ' $n$ ander instansie oorgedra word. ${ }^{39}$ ' $n$ Ander organisasie sal dalk nie dieselfde sentiment jeens die Gedenkteken openbaar as die SANW nie. In 'n skrywe KMDMT N-TVL/V/517/5 dd 1 April 1993 gee die Bevelvoerder van Kommandement Noord-Transvaal te kenne dat die oordrag van die forte onderhewig is aan die volgende voorwaardes:

a. Wanneer die Stadsraad die forte oorneem sal hy verantwoordelik wees vir die voortgesette instandhouding van die forte.

b. Die SANW behou die reg van toegang tot die Soldatemonument. ${ }^{40}$

Die voortgesette toegang tot die Gedenkteken impliser dan dat die aan bring van die name op die ererol voortgesit moet word. ${ }^{41}$ Afdeling Personeel se Dokumentasiediens was tot 1993 verantwoordelik vir die instandhouding en opdatering van die ererol by Fort Klapperkop.

Rondom die bestaansreg van die Soldatemonument en die ererol kan daar twee uiteenlopende gedagterigtings geïdentifiseer word. Aan die een kant is daar ' $n$ groep mense wat redeneer dat alhoewel die Gedenkteken ' $n$ huldeblyk aan alle gesneuwelde SAW lede (ongeag velkleur) is, dit nogtans gesien word as ' $n$ monument wat oorwegend gekoppel kan word aan ' $n$ periode in die geskiedenis van die blanke bevolking van SA. Met die aanvang van ' $n$ nuwe politieke era kan só ' $n$ monument derhalwe as polities sensitief beskou word en kan geredeneer word dat dit beter sal wees om die aanbring van die name by die Gedenk-

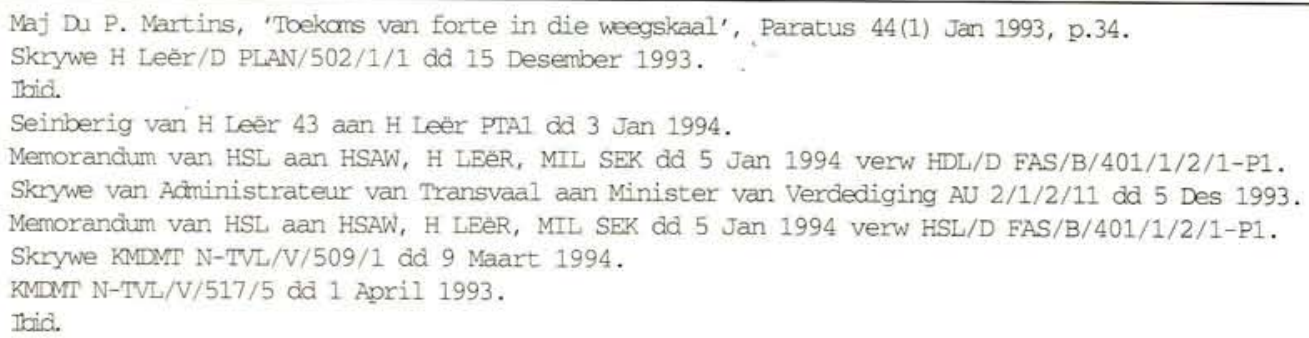


teken te staak. Die SANW is ook nie meer amptelik in ' $n$ oorlog teen terrorisme betrokke nie en dit wil voorkom asof die meeste persone wie se name die afgelope twee jaar by die ererol aangebring is eerder in voertuigongelukke omgekom het.

Daarteenoor is daar ' $n$ groep mense wat die mening toegedaan is dat die SANW ' $n$ verantwoordelikheid jeens die Gedenkteken het aangesien die SANW gemoeid was met die oprigting en instandhouding daarvan. Daar moet egter onthou word dat ons vandag in ' $n$ ander tyd en onder ander omstandighede lewe as tydens die oprigting van die Gedenkteken veranderde omstandighede stel ander eise aan ons. Tog wil dit voorkom asof ekonomiese oorwegings (fondse, personeel) op die ou einde die laaste sê gaan hê oor die voortbestaan van die Gedenkteken.

Sedert die skryf van hierdie artikel, het dit bekend geword dat die Stadsraad van Pretoria die forte Schanskop en Klapperkop van die Staat gaan koop en ontwikkel. Dié besluit is op 28 Maart 1994 geneem.

Redakteur 